\title{
Teaching Children and Parents to Understand Dog Signaling
}

\author{
Kerstin Meints ${ }^{1 *}$, Victoria Brelsford ${ }^{1}$ and Tiny De Keuster ${ }^{2}$ \\ ${ }^{1}$ School of Psychology, University of Lincoln, Lincoln, United Kingdom, ${ }^{2}$ Department Nutrition, Genetics and Ethology, \\ Faculty of Veterinary Medicine, Ghent University, Ghent, Belgium
}

Safe human-dog relationships require understanding of dogs' signaling. As children are at particularly high risk of dog bites, we investigated longitudinally how children from 3 to 5 years and parents perceive and interpret dogs' distress signaling gestures. All participants were then taught how to link their perception of the dog with the correct interpretation of dogs' behavioral signals and tested again. Results show a significant increase in learning for children and adults, with them showing greater understanding of dogs' signaling after intervention. Better learning effects were found with increasing age and depended on the type of distress signaling of the dogs. Effects endured over time and it can be concluded that children and adults can be taught to interpret dogs' distress signaling more correctly. Awareness and recognition of dogs' stress signaling can be seen as an important first step in understanding the dog's perspective and are vital to enable safe interactions.

\section{OPEN ACCESS}

Edited by:

Peggy D. McCardle,

Consultant, New Haven, CT, United States

Reviewed by:

Aubrey Howard Fine, California Polytechnic State University, United States Esther Schalke, Lupologic GmbH, Germany

${ }^{*}$ Correspondence: Kerstin Meints kmeints@lincoln.ac.uk

Specialty section:

This article was submitted to Veterinary Humanities and Social

Sciences,

a section of the journal

Frontiers in Veterinary Science

Received: 08 June 2018 Accepted: 28 September 2018 Published: 20 November 2018

Citation:

Meints $K$, Brelsford $V$ and $D e$ Keuster T (2018) Teaching Children and Parents to Understand Dog Signaling. Front. Vet. Sci. 5:257. doi: 10.3389/fvets.2018.00257
Keywords: children, adults, dog body language, dog bite prevention, safety intervention

\section{INTRODUCTION}

Benefits of dog ownership include positive effects on human health and well-being and on child development and learning [see (1) for overview; for recent systematic reviews, see $(2,3)$ ]. Dogs function as social facilitators (4), assist in therapy, are used as co-visitors in retirement and care homes, in nurseries and in hospitals (1). Pets are seen as friends, companions and social partners (58 ) and, increasingly, as family members $(5,6)$. Dogs are among children's favorite pets and children show most attraction to dogs, be it puppies or grown-up dogs, compared to other pets $(9,10)$.

In the UK around $30 \%$ of households own a dog, with regional fluctuations in numbers (21$38 \%$ ) (11-13), while in the US and in Australia up to about $40 \%$ of households own a dog $(5,14)$. The dog is also the pet of choice in many pet-owning households in Europe and Canada, with even higher figures in Mexico, Argentina and Brazil (15).

However, despite the benefits of dog ownership, there are also risks involved. Hospital data revealed that each year, about $1.5 \%$ of the general population suffers a dog bite that requires medical attention $(16,17)$ and the prevalence of dog bites in children is twice that of other age groups $(18-20)$.

In the UK, a clear increase in the number of people attending a minor injury unit or accident and emergency department for treatment of dog bites and strikes has been observed. Over the tenyear period March 2005 to February 2015 the number of admissions due to dog bites increased $76 \%$ from 4,110 per year to 7,227 . This is a $6.5 \%$ increase from the 6,783 finished admission episodes recorded in the previous 12 months (21). With the highest rate of dog bite injuries occurring in children (22-24), Schalamon et al. (25), demonstrated that most injuries occur in those under 15 years of age, with rates peaking between the ages of 5-9 years. Recent figures from the National Health Service on dog bites and strikes $(21,24,26)$ demonstrate that more serious dog 
bite injuries requiring admission to hospital are on the increase, with $17 \%$ being related to children under the age of 10 years. Furthermore, dog bite rates in most-deprived compared to leastdeprived areas are three times as high $(21,24)$.

However, the above estimate is low as these figures for adults and children do not include unreported cases were treatment was not required or where injuries were not presented to the medical profession $(27,28)$. Strikingly, when interviewed directly, about $47 \%$ of school children reported they had been bitten $(28,29)$. In a recent survey in the UK, Westgarth et al. (30) found that a quarter of their local sample of 694 adult respondents had suffered a dog bite.

High dog bite figures are not unique to the UK: the problem of dog bite injuries is a world-wide problem (31) with research from Australia (20), the Netherlands (23), Alaska (32), Belgium (33), Switzerland (18), Canada (34), and Spain (35) highlighting the extent of the issue. A recent study carried out by Quirk (27) estimated that $1,615,426$ persons were treated in US emergency departments for non-fatal dog bite-related injuries between 2005 and 2009.

Costs caused by dog bite incidents are estimated at around $\$ 53.9$ million for hospital stays only in the US (36), with home owners insurance claim payments reaching \$530 million in 2014 (37). Likewise, costs in Australia were estimated around \$7

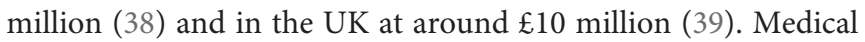
and veterinary professionals have repeatedly demanded effective prevention [e.g., (40)] and a collaborative (41) and evidencebased strategy $(42,43)$.

The majority of bite accidents (about 75\%) occur in the home environment and involve children bitten by a familiar dog [e.g., (25), (44-47)]; see also (48) for similar data on adults]. Childinitiated interactions, such as approaching the dog while eating or surprising it while sleeping, seem to trigger up to $86 \%$ of accidents at home (44). Recent questionnaire studies also showed that injuries occurred during feeding treats or play (49).

Younger children are more often injured in the face, neck and upper torso $(25,46,50)$. It has also been reported that $43 \%$ of patients on a maxillofacial ward for treatment after a dog bite were children under the age of 10 (40). Such injuries can lead to life-threatening medical conditions or psychological sequelae like Post-Traumatic Stress Disorder $(51,52)$. Whilst physical injuries are apparent, the psychological impact is less obvious, and left untreated can have long term consequences, not only for the victim but also their family (52). Seventy percent of all fatal dog bites involve children $(53,54)$.

Given these high figures, and given that most of the time, the child's interaction with a dog triggers the biting incident there is a clear need to increase parent awareness about home contexts and child actions that may trigger a dog bite $(55,56)$. There is also a need to improve the child's ability to assess how a dog responds to their action and for them to learn when it is not safe to interact with a dog. For appropriate supervision of children and dogs, it is also important for parents to be aware of the dog's signaling as reaction to their or their children's interactions with the dog.

Surprisingly, children as well as adults often do not notice dogs' stress signaling or misinterpret dogs' attempts to signal (5759). When shown images of dogs' facial displays, children often do not understand dogs' facial expressions and can confuse a very angry dog as being friendly and approachable (60). Without tuition, children do not discriminate dogs' body signals and tend to look mainly at the face instead (61). In adults, dog signaling interpretations vary with experience, however, dog ownership does not predict correct understanding of dogs' behavior [e.g., $(62,63)]$.

Overall, research has demonstrated that there is little knowledge regarding dog behavior and safety practices for childdog interactions [see also $(64,65)]$. When trying to enable safe human-animal interaction, it is vital to be able to recognize and interpret the animal's distress signaling correctly in order to avoid injury to the person and distress to the animal. Arhant et al. (49) also emphasize the need for a dog bite prevention approach directed at caregivers.

While dog bite prevention programmes exist, and some address how to behave in public with unfamiliar dogs [e.g., $(18,66,67)$, see $(68)$ for a systematic review], while others teach children and their families to be aware of potential risk situations with a family dog, and how to avoid or de-escalate risk situations [e.g., Blue Dog bite prevention program assessment; see $(56,69)]$ there is no assessed program so far that teaches children or adults more basic skills-how to recognize and interpret specific dog body language. More precisely, currently no intervention has been tested to teach children and adults about dogs' behavioral response and their stress signals as a response to the child or adult in the context of a dog-directed action.

Humans often perceive petting a dog or hugging a dog as friendly gestures. Especially young children like to hug dogs as a sign of their friendship, not realizing that their (benign) actions might intimidate a dog and induce fear or distress. If a dog freezes and does not move, this may lead parents and teachers to think the dog feels happy with this well-intended attention. Thus, when targeting dog bite prevention in families with children and their pet dog, it is crucial to realize that safe cohabitation is based on mutual understanding of species-specific signaling, social gestures and interactions (70). Research indicates that most of the dog bite accidents with family dogs result from such seemingly benign (from the human perspective) interactions, hence the importance to stimulate awareness in children and parents about how their dog behaves, and which signals the dog presents when being hugged, petted or approached in different situations (55). Recent research has shown that most of children's interactions with dogs fall into this category, and mostly increase in frequency with age (49).

Dogs who feel stressed are likely to present stress- and threatavoiding signaling (e.g., nose-licking, turning away). When these signs are ignored or misinterpreted, the pet may use other strategies, including aggression [(71-73); see also Mariti et al. (74) for a first systematic empirical investigation of such behaviors in dogs]. Recent studies have shown further evidence that dogs show signals like licking of lips and looking away as appeasement signals in dog-human communication [(75); see also (76)].

Shepherd's "ladder" of distress signals $(72,73)$ includes conflict-defusing signals on its lower steps (appeasement behavior, calming signals, displacement behavior, e.g., nose-licking, eye-blinking) - these are signals to defuse conflict and restore 
harmony in a social interaction. In the next grouping on the ladder, conflict-avoiding signals are included (e.g., walking away, standing crouched, tail tucked under, creeping). In case a perceived social threat continues, and/or conflict-defusing avoiding strategies have failed, dogs may present strategies higher on the ladder such as conflict escalation signals (e.g., staring, growling, biting). For an overview, see Figure 1.

It is important to stress that Shepherd's ladder is not to be understood in a strictly hierarchical way as dogs do not necessarily move through these signals in a linear fashion. Depending on how the interaction evolves (i.e., if the approaching human understood the message correctly, and by stopping all interaction with the dog, the dog may be able to relax and return to a state of comfort) and depending on what the dog has learnt (e.g., unpleasant outcome of interactions in the past despite conflict-avoiding signaling), their strategy may change over time, and dogs may move on to a snap or bite action to stop a perceived threat.

It is also vital to be aware that dogs' strategies depend on factors relating to the context (social \& environmental triggers),

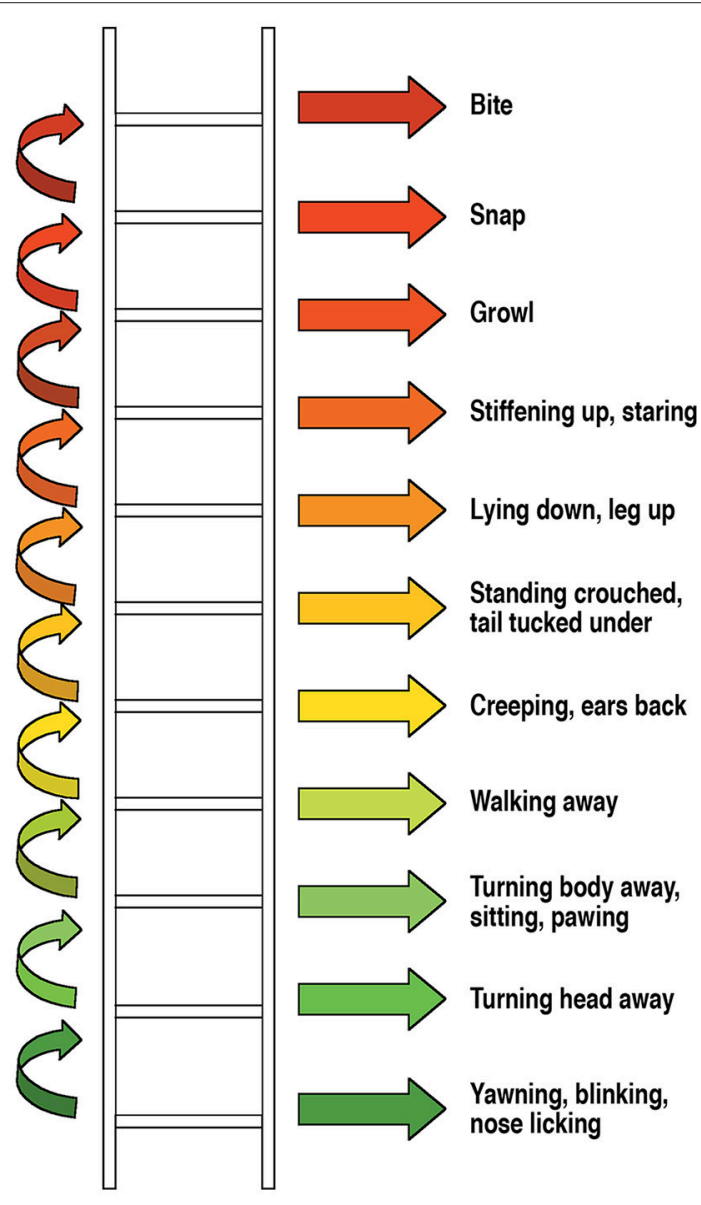

FIGURE 1 | How a dog can react to stress or threat, Shepherd (2002, 2009), used with permission from BSAVA Manual of Canine and Feline Behavioural Medicine, 2nd edition (2009). factors relating to the dog e.g., personal history (past experiences) and on their physical and behavioral health. It is important to stress that factors that are known to reduce a dog's wellbeing will reduce a dog's threshold for stress and arousal and increase the odds of using escalation strategies in a stressful encounter. Wellknown examples are sensory deficits, physical illness, chronical pain or dogs suffering from anxiety $(45,47,77)$. In addition, other signals may be shown [e.g., $(57,71,74)]$.

There is a striking lack of knowledge of dog signaling in the population, and there is also a general lack of knowledge regarding dog behavior and safety practices for child-dog interactions, with owners of dogs often unaware of the factors likely to increase the risk of dog bites to children (64), for example, subtle signals are often not known by dog owners to be stress signals (58). This is a serious knowledge gap, as the safety of young children mainly relies on the perceptual understanding, and knowledge and anticipatory guidance of the adults around them $(47,64)$. The following steps are often named to constitute a more complete process of prevention and action:

Step 1 Knowledge of stress signaling

Step 2 Recognition and correct interpretation of stress signaling

Step 3 Adapt the action: awareness of the situation and insight to act accordingly

Step 4 Repeat - Recognition of future contexts and avoidance of risk (78).

Thus, while dogs are rather good at interpreting human signaling [e.g., (79-92)], humans do not seem to be equally equipped to interpret dog's visual signaling.

Given not only the popularity of dogs as pets, also the increasing popularity of animal-assisted interventions in educational settings as well as the application of pets in the classroom [(93); for a systematic review, see (2); see also (1, 9499)], and given the frequency of injury with familiar dogs at home, there is an urgent need to teach adults and children dog body language.

In order for children to interact safely with dogs, they must first have knowledge of dog behavior and awareness of situations which may put them at risk of being bitten. This means that they must know the signals, recognize them, understand that they are the consequence of actions toward the dog, and, if it is their own action, adapt their action. Ultimately, it is crucial that parents also have this knowledge in order to teach and supervise their children when interacting with dogs and to provide anticipatory guidance.

If we can successfully teach children and parents to recognize and interpret dogs' stress signaling correctly, and be aware of the actions that trigger the signaling, and ideally, act upon their knowledge, then all sides will profit: adults and children will understand dogs' distress signaling better, risk situations may be defused and the (family) dog will enjoy more respectful and appropriate treatment.

In the current study, we have addressed the lack of knowledge and lack of systematic intervention with children and adults alike. By teaching participants how to recognize and interpret dog stress signals and by assessing if our intervention works, we are 
undertaking the first steps toward preventing misunderstandings and risk escalation due to lack of knowledge.

We assessed participants' knowledge of dogs' signaling behaviors before and after a dog body language intervention with a range of video clips of real dogs. We tested both children and parents. In addition, we integrated this into a longitudinal design to monitor the effectiveness of the current intervention by assessing children's developmental progression over 4 time points up to 1 year. Finally, to gain more in-depth knowledge of other potential factors, we used questionnaires to learn about background demographic data, socio-economic status and dog ownership statistics.

\section{METHODS}

\section{Participants}

Children were recruited through schools and nurseries in the county of Lincolnshire, UK. All participants were healthy and had normal or corrected-to-normal vision. No exclusions occurred before testing.

Initial calculations with Poweranalysis [G*Power3; (100)] showed a necessary sample size of 18 children per age group (3, 4 , and 5 years). As attrition rates of about $30-70 \%$ do occur in longitudinal studies and often reduce the initial cohort to a vastly smaller size in the final cohort (101), we over-recruited children to be able to cope even with a harsher drop-out rate. Hence, our initial overall group size at Test 1 contained 124 children for this longitudinal study. However, our attrition rate was very low and we managed to keep $82 \%(N=101)$ of children in the sample after 6 months and we retained $85 \%(N=105)$ of children in the final sample after 1 year as can be seen in the following Table 1.

Children took part in Test 1, 2, 3, and 4. Reasons for attrition in children are as follows: In Test 2, 3 children who took part in Test 1 did not complete Test 2 on the same day, hence were excluded from analysis. Test 3: Attrition of 20 children due to being ill, having moved school and being on holiday. Test 4: A slight gain of children occurred, as some who had missed Test 3 due to absence were back for Test 4 .

Overall, in the final sample entered into the data set, there are 88 children who took part in all testing sessions ( 39 girls and 49 boys overall; 263 -year-olds ( $12=$ female, $14=$ male; $M=3.4$, $S D=.32$, range 2.8-3.9), 23 4-year-olds (11 female, 12 male; $M=4.6, S D=.24$, range 4.0-4.9) and 39 5-year-olds (16 female, 23 male; $M=5.7, S D=.45$, range 5.0-6.8). Of this sample, $37 \%$ had a dog.

Parents took part in Test 1 and 2 (same day) only. Additional longitudinal parent testing was not possible due to limited funding. However, piloting had shown that adults showed clear improvements as they found the teaching phase to be a real "eye-opener." Error rates dropped once they had realized what the behavior of the dog implied. The current study results confirm this and we have no reason to assume that adults with typical and intact memory capacity would forget this knowledge over time. Of the parents $27.5 \%$ were dog owners, these dog ownership figures for children and adults compare well with the national average of about $30 \%$ dog owners. Also, $47.5 \%$ of parents had been bitten by a dog, this is very
TABLE 1 | Participant numbers over time.

\begin{tabular}{|c|c|c|c|c|}
\hline & $\begin{array}{l}\text { Test } 1 \\
\text { (baseline) }\end{array}$ & $\begin{array}{l}\text { Test } 2 \\
\text { (same day) }\end{array}$ & $\begin{array}{l}\text { Test } 3 \\
\text { (6 months } \\
\text { later) }\end{array}$ & $\begin{array}{l}\text { Test } 4 \\
\text { (1 year later) }\end{array}$ \\
\hline $\begin{array}{l}\text { Age } \\
\text { groups } \\
\text { at start }\end{array}$ & $\begin{array}{l}124 \text { children } \\
\text { ( } N \text {, mean, range } \\
\text { and SD) }\end{array}$ & 121 children & 101 children & 105 children \\
\hline 3 years & $\begin{array}{l}N=44 \\
(17 \text { females, } 27 \\
\text { males, mean } \\
\text { age }=3.4, \text { age } \\
\text { range; } 2.8-3.9, \\
S D=.3 \text { ) }\end{array}$ & $\begin{array}{l}N=42, \\
(17 \text { females, } 25 \\
\text { males, mean } \\
\text { age }=3.4, \text { age } \\
\text { range; } 2.8-3.9, \\
S D=.3 \text { ) }\end{array}$ & $\begin{array}{l}N=31 \\
(12 \text { females, } 19 \\
\text { males, mean } \\
\text { age }=3.9, \text { age } \\
\text { range; 3.4-3.9, } \\
S D=.4)\end{array}$ & $\begin{array}{l}N=34, \\
(15 \text { females, } 19 \\
\text { males, mean } \\
\text { age }=4.5, \text { age } \\
\text { range; } 4.0-5.1, \\
S D=.3 \text { ) }\end{array}$ \\
\hline 4 years & $\begin{array}{l}N=31 \\
(15 \text { females, } 16 \\
\text { males, mean } \\
\text { age }=4.6, \text { age } \\
\text { range; } 4.0-4.9, \\
S D=.2)\end{array}$ & $\begin{array}{l}N=30 \\
(14 \text { females, } 16 \\
\text { males, mean } \\
\text { age }=4.6, \text { age } \\
\text { range; } 4.0-4.9, \\
S D=.2)\end{array}$ & $\begin{array}{l}N=29 \\
(14 \text { females, } 15 \\
\text { males, mean } \\
\text { age }=5.0, \text { age } \\
\text { range; } 4.4-5.4, \\
S D=.2)\end{array}$ & $\begin{array}{l}N=24 \\
(11 \text { females, } 13 \\
\text { males, mean } \\
\text { age }=5.6, \text { age } \\
\text { range; } 5.2-5.9, \\
S D=.2)\end{array}$ \\
\hline 5 years & $\begin{array}{l}N=49 \\
(23 \text { females, } 26 \\
\text { males, mean } \\
\text { age }=5.7, \text { age } \\
\text { range; } 5.0-6.8, \\
S D=.4)\end{array}$ & $\begin{array}{l}\text { Same as at } \\
\text { Test } 1\end{array}$ & $\begin{array}{l}N=61 \\
(18 \text { females, } 23 \\
\text { males, mean } \\
\text { age }=6.2, \text { age } \\
\text { range; } 5.5-7.3, \\
S D=.5)\end{array}$ & $\begin{array}{l}N=47 \\
(22 \text { females, } 25 \\
\text { males, mean } \\
\text { age }=6.0, \text { age } \\
\text { range; } 5.8-7.8, \\
S D=.5)\end{array}$ \\
\hline Adults & $\begin{array}{l}40 \text { parents }(8 \\
\text { males, } 32 \\
\text { females, mean } \\
\text { age }=38.9 \\
\text { years; } \\
S D=4.9 \text { ) }\end{array}$ & $\mathrm{n} / \mathrm{a}$ & $\mathrm{n} / \mathrm{a}$ & $\mathrm{n} / \mathrm{a}$ \\
\hline
\end{tabular}

similar to the $47 \%$ reported elsewhere [e.g., (29)]. Thus, we can assume our sample is fairly representative concerning these factors.

\section{Ethical Approval}

This study was carried out in accordance with the recommendations of University of Lincoln, School of Psychology Research Ethics Committee (SOPREC). The protocol was approved by the SOPREC. Written informed consent was gathered in accordance with the Declaration of Helsinki.

\section{Stimuli Video Clips}

The stimuli consisted of sets of 16 short video-clips portraying dogs with the full range of behavioral distress signals described in "Shepherd's ladder" $(72,73)$. These are as follows: yawning, blinking, nose licking, turning the head away, turning the body away, pawing, walking away, creeping, crouching with tail tucked under, lying down with legs up, stiffening up and staring, growling, snapping and biting. Due to other literature, we also added snarling and walking away with hiding. We also presented four video clips of relaxed dogs. Given research indicating that acoustic input may help children's recognition and correct interpretation $(102,103)$, those clips that naturally had a sound (snarling and growling) were accompanied by this sound. 
Due to ethical considerations we did not show serious bites drawing blood, and parents had the opportunity to view the images beforehand and decide if they allowed their children to take part. Also, children received a thorough debriefing session after testing finished, so we could make sure children clearly understood the dog signaling. None of the children displayed any signs of distress during testing or after testing, none of the parents reported any detrimental effects back to the research team.

Having piloted the video clips, we decided that the procedure worked best if we used $2 \times 16$ videos ( 2 per distress behavior)we added 4 relaxed (happy) behaviors so that children would not get the impression that dogs are usually distressed, however, these items were not part of the intervention phase and children were not trained to recognized relaxed dogs ${ }^{1}$.We called these "happy" as the language needed to be child-appropriate and previous work has shown that children understood this label well, similar for the terms "ok," "unhappy," and "angry" (60).

Videos were clipped and resized using Bink and Smacker (RAD Video Tools): each video was 6,000 ms duration, $360 \times 240$ pixels, and with a data rate of 25 frames per second.

Video clips were presented centrally on the monitor screen and displayed on a $15 \%$ greyscale background. Altogether, we used up to 4 different sets of videos in Test 1 (baseline), Test 2, 3 , and 4 (see below). All video stimuli were assessed for their expression and approved by 3 internationally renowned dog behavior specialists.

\section{Audio Stimuli}

Audio recordings matching each of the visual stimuli were produced in a sound-proof professional audio-recording studio at the University. All recordings were carried out within one session so as to reduce variation in the voice of the speaker. The speaker was female and a native speaker of British English. Audio messages consisted of four features across all trials: an initial "Look" command, followed by a description of the dogs' behavioral signal to steer participants' attention, then a message of how the dog is feeling and lastly a message of safety instruction for the child. We have consulted closely with a consultant and dog behavior expert on the appropriate content of the verbal messages. Messages take the following character: (a) Attention getter (Look!), (b) highlighting the dog's signaling behavior, (c) followed by an explanation how to interpret the dog's behavior, (d) then a clear safety instruction for adapting their actions. An example of such a message is as follows: "Look! The dog is blinking its eyes. The dog is worried. You should leave the dog alone." Audio files were cut and manipulated using Audacity version 2.0.1. Files were $1141 \mathrm{kbps}, 2$ channel and were used in .wav format.

\section{Rating Scale}

We used a child-appropriate 1-5 rating scale in which symbolic faces expressed either very happy (1), happy (2), just ok (3),

\footnotetext{
${ }^{1}$ Incidentally, our behavior experts agreed least on "happy" dogs. In order to teach about relaxed dog behavior, we would need to set up a separate study investigating this. For the current research, we analyzed the behaviors that were trained in the intervention to see if we can educate participants on recognizing distress behaviors in dogs.
}

unhappy/angry (4), and very unhappy/angry (5) emotions. Children had no problems using the scale.

\section{Procedure}

Children were tested in schools and nurseries in a quiet room. Videos were presented on a laptop and the experiment was programmed using the Lincoln Infant Lab Package 1.0 (104). Participants were seated approximately $70 \mathrm{~cm}$ from the screen.

Child participants took part in the study longitudinally; this included viewing an initial baseline phase of video stimuli (Test 1 ), immediately followed by a training phase of videos and then tested with novel videos (Test 2) afterwards to investigate if their knowledge had improved. Participants were then tested again 6- and 12 months later (Test 3 and 4) without any additional training to see if they had retained their knowledge. Hence, we have an integrated control group with each child being their own control (before and after learning and at the follow-up testing). In addition, we have further integrated controls in that 4-yearolds at testing start can be compared with 3-year-olds after 1 year (when they have turned 4 years of age). In the same way, the 5-year-olds at start of their testing can be compared with the 4 -year-olds at testing point 1 year (when they have turned 5). Adults only took part twice on the same day (Test 1, Training and Test 2) and results can therefore be compared before and after testing.

\section{Testing Phases \\ Baseline phase}

Each participant viewed 20 trials. Each trial was made up of a $6,000 \mathrm{~ms}$ video displaying dog behavioral signals as described above. These were followed by a fixed choice user/child friendly rating 1-5 scale ranging from "very happy" to "very unhappy/angry." Participant ratings were recorded both electronically and verbally, and the rating scale stayed on the screen until the participant had made their choice. Duration of this phase was between 2 and $5 \mathrm{~min}$.

\section{Training phase}

Participants viewed 32 trials $(2 \times 16$ distress behaviors, one set with dogs seen in Test 1, one set with novel dogs). Each trial was made up of a $1,000 \mathrm{~ms}$ blank screen accompanied by the initial "Look" audio. This was followed by a $6,000 \mathrm{~ms}$ video displaying dog behavioral signals accompanied by the remainder of the audio sentence highlighting the dogs' behavioral stress. Duration of this phase is about $4-5 \mathrm{~min}$.

\section{Test 2 (same day) and Test 3 and 4 (6- and 12-month intervals)}

Participants were again presented with 20 trials (16 distress behaviors and an additional 4 "happy" dogs). This was immediately followed by the fixed choice user/child friendly rating 1-5 scale as described above. This took between 2 and $5 \mathrm{~min}$. Both, children and parents thoroughly enjoyed taking part.

Note: In addition, half of the children always saw novel stimuli at each testing time, and the other half saw the novel set from Test 2 repeated at Tests 3 and 4 . This was to explore if children learn 
differently with items that are novel each time as opposed to items that are novel at Test 2 and then reoccur, however, there was no statistical difference, hence, results below include both groups of stimuli.

\section{RESULTS}

\section{Study 1 With Children}

\section{Rating Scores Children}

We initially calculated a repeated measures ANOVA with Gender (male/female), Dog Ownership (yes/no), Age Group (3, 4, 5 years) and Distress Signal Group (defuse, avoid, escalate) on the rating scores at different Testing times (before training, after training, after 6 months, after 1 year $)^{2}$. This analysis revealed no significant effects of Gender and Dog Ownership, hence we calculated a repeated measures ANOVA only with Age Group (3, 4, 5 years) and Distress Signal Group (conflict defusing, conflict avoiding, conflict escalating) on the rating scores at the different testing times (before training, after training, after 6 months, after 1 year).

We found a highly significant main effect of Age $\left[F_{(2,85)}=7.84, p<.001\right.$, partial $\left.\eta^{2}=.16\right]$ with older children showing more correct results than younger children. A significant main effect of Distress Signal Group $\left[F_{(2,170)}=298.85, p<.001\right.$, partial $\eta^{2}=.78$ ] also emerged, with children judging conflict escalating signals as different from conflict-avoiding and defusing signals, but not distinguishing between conflictavoiding and defusing signals in dogs-post hoc tests with Bonferroni corrections $(p<.0166)$ show that the following differences are highly significant: conflict-escalating vs. conflictdefusing $(p<.001)$; conflict-escalating vs. conflict-avoiding $(p<.0001)$; while children do not distinguish conflict-defusing vs. conflict-avoiding signals in dogs $(p<.05)$.

We also found a highly significant main effect for Testing times $\left[F_{(3,255)}=6.93, p=.0002\right.$, partial $\left.\eta^{2}=.08\right]$ with children improving significantly from Test 1 (baseline measure before intervention) to Test 2 after intervention $(p<.002)$. Children also show improved knowledge from Test 1 to Test 3 at 6 months $(p<.0026)$ and from Test 1 to Test 4 after 1 year $(p<.0006)$.

There was also a significant interaction between Age group and Testing Times $\left[F_{(6,255)}=5.11, p=.0001\right.$, partial $\left.\eta^{2}=.11\right]$ which demonstrated that the older the participants, the better they perform. Highly significant interactions of Age by Distress Signal $\left[F_{(4,170)}=5.07, p=.0007\right.$, partial $\left.\eta^{2}=.11\right]$, see Figure 2 below, and of Distress Signal by Testing Time $\left[F_{(6,510)}=6.02\right.$, $p<.0001$ partial $\eta^{2}=.07$ ] also emerged as well as a significant three-way interaction between Testing time, Distress Signal and Age $\left[F_{(12,510)}=1.94, p=.028\right.$, partial $\left.\eta^{2}=.04\right]$ showing clear differences between conflict-escalating signals vs. conflictdefusing and avoiding signals, with children showing better performance with increasing age and improvement over time, especially in the conflict-escalating signal group.

\footnotetext{
${ }^{2}$ See Norman (105) and Carifio and Perla (106) for the appropriateness of using
} Likert-scale data with ANOVAs.

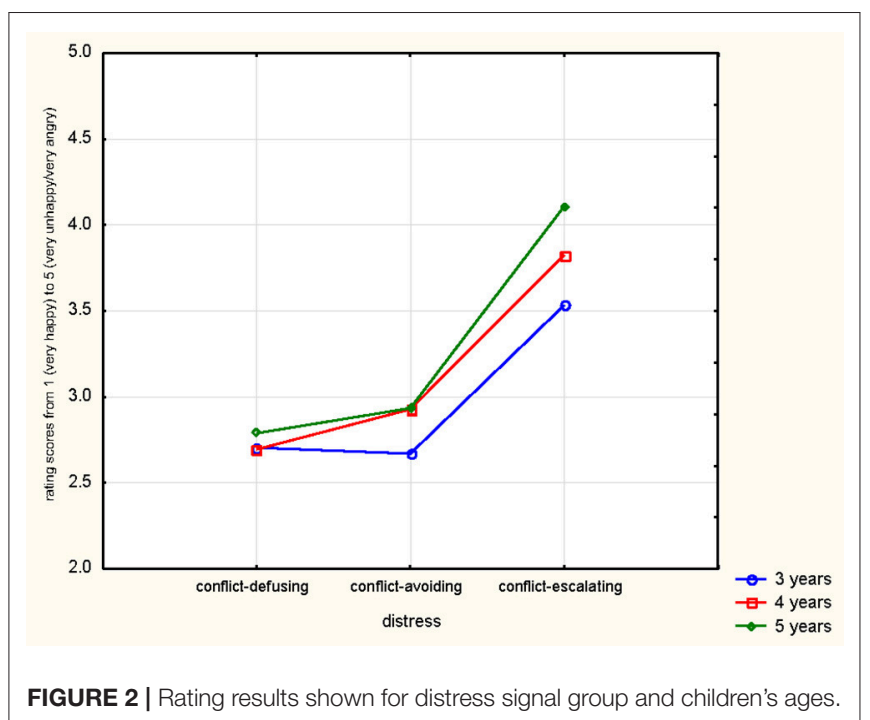

These results show medium to high effect sizes. Results are illustrated in overview in Figures 2, 3.

After the intervention, children improve in their judgments, but even the oldest children do not come close to the correct ratings (e.g., 5 for conflict-escalating signal, 1 for happy).

\section{Study 2 With Adults}

Rating Scores Adults

An ANOVA of Gender (male/female) by Dog Ownership (yes/no) by Distress Signal group (conflict-defusing, conflictavoiding, conflict-escalating) was calculated for Testing Times before and after intervention on rating scores. Gender and Dog Ownership yielded no significant results, therefore the analysis was calculated with Distress Signal group (conflict-defusing, conflict-avoiding, conflict-escalating) and Testing Times before and after intervention. We found a highly significant main effect for Testing Time $\left[F_{(1,39)}=243.93, p=.0001\right.$, partial $\left.\eta^{2}=.86\right]$ showing improved understanding after intervention and a highly significant main effect for Distress Signal group $\left[F_{(2,78)}=291.54, p=.0001\right.$, partial $\left.\eta^{2}=.88\right]$ highlighting differences between Distress Signal groups. Figure 4 below illustrates this.

After the intervention, adults come close to the ratings that would be suitable for the dog's signaling attempt (5 for conflict-escalating signals, 4-4.5 for conflict-avoiding signals, 4 for conflict-defusing signals).

We also tested if there were effects for parental education, but no significant results existed.

\section{Studies 1 and 2: Rating Scores Compared Children and Adults}

We also found highly significant main effects on differences between the parents' and children's judgments of dog's behavior, with most mistakes occurring in the conflict-defusing and conflict-avoiding signal groups $\left[F_{(3,387)}=251.69 ; p<.0001\right]$. 

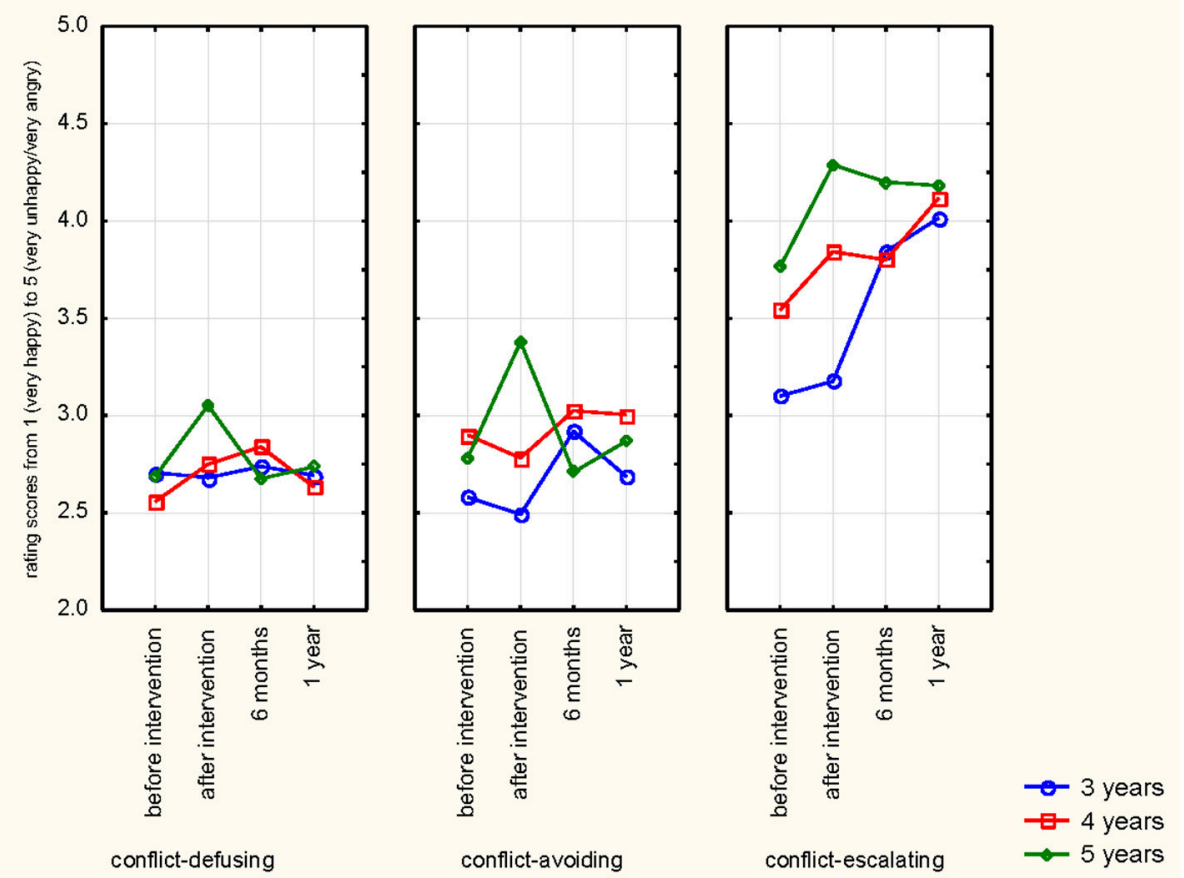

FIGURE 3 | Overview of all results: Rating results for distress signal group and children's ages over time.

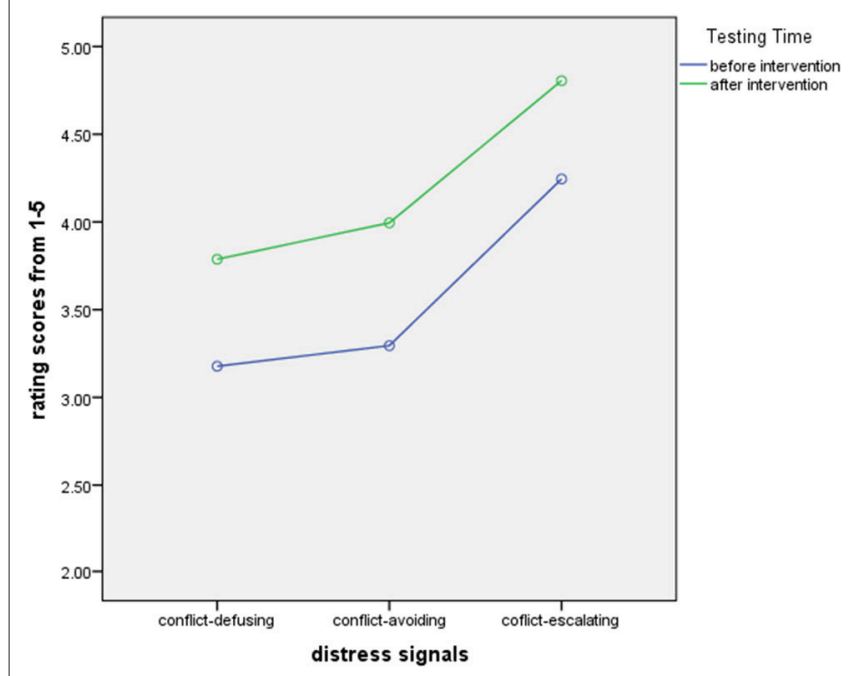

FIGURE 4 | Rating scores for adults by distress signal group before and after intervention.

\section{Expected vs. Obtained Scores}

One-sample $t$-tests revealed that all age groups significantly underestimate and misinterpret the dogs' real distress signaling $(p<.001)$. Again, younger children make most misinterpretations. Least recognition of different distress signaling is found in 3-year-old children.

\section{Studies 1 and 2: Correct Answers and Errors}

In a further analysis, we calculated correct responses and errors from the original scores. Table 2 below shows percentages of correct answers and errors per Distress Signal category ${ }^{3}$. Please note the high proportion of errors classed as "happy" by the participants.

\section{Correlations Between Children's and Parents' Responses}

There were no significant correlations between children's and their parents' judgments of the dogs' signaling behaviors before or after training.

\section{Correct Answers and Errors - Children}

We also calculated a repeated measures Anova of Gender (male/female) by Dog Ownership (yes/no) by Age Group (3, 4 , 5) by Distress Signal Group (conflict-defusing, conflictavoiding, conflict-escalating) before and after Intervention (Test $1,2,3$, and 4) on correct answers. As there were no effects of dog ownership or gender, we ran the analysis with Age

${ }^{3}$ For the purpose of scoring \% correct, we have scored "unhappy/angry"(4) as correct for conflict-defusing distress, and have accepted both, "unhappy/angry" (4) and "very unhappy/very angry"(5), as correct for conflict-avoiding distress and conflict-escalating distress. In a stricter analysis below, we have only accepted "very unhappy/very angry" (5) as correct for highly distressed dogs. Here, we have accepted both 4 and 5 for highly distressed dogs (instead of just accepting $5 \mathrm{~s}$ ) due to adults known reluctance to give extreme measures for emotional stimuli [e.g., (107)]. 
TABLE 2 | Correct answers and errors in \% over time for children and adults.

\begin{tabular}{|c|c|c|c|c|c|c|c|c|}
\hline & \multicolumn{2}{|c|}{ Pre-training } & \multicolumn{2}{|c|}{ Post-training } & \multicolumn{2}{|c|}{ After 6 months } & \multicolumn{2}{|c|}{ After 1 year } \\
\hline & Correct & Error & Correct & Error & Correct & Error & Correct & Error \\
\hline \multicolumn{9}{|c|}{ CONFLICT ESCALATING SIGNALS } \\
\hline 3 years & $47 \%$ & $\begin{array}{c}53 \% \\
\text { "happy" } \\
65 \%\end{array}$ & $50 \%$ & $\begin{array}{c}50 \% \\
\text { "happy" } \\
58 \%\end{array}$ & $64 \%$ & $\begin{array}{c}36 \% \\
\text { "happy" } \\
56 \%\end{array}$ & $66 \%$ & $\begin{array}{c}34 \% \\
\text { "happy" } \\
58 \%\end{array}$ \\
\hline 4 years & $55 \%$ & $\begin{array}{c}45 \% \\
\text { "happy" } \\
50 \%\end{array}$ & $72 \%$ & $\begin{array}{c}28 \% \\
\text { "happy" } \\
69 \%\end{array}$ & $70 \%$ & $\begin{array}{c}30 \% \\
\text { "happy" } \\
62 \%\end{array}$ & $76 \%$ & $\begin{array}{c}24 \% \\
\text { "happy" } \\
41 \%\end{array}$ \\
\hline 5 years & $64 \%$ & $\begin{array}{c}36 \% \\
\text { "happy" } \\
52 \%\end{array}$ & $83 \%$ & $\begin{array}{c}17 \% \\
\text { "happy" } \\
43 \%\end{array}$ & $77 \%$ & $\begin{array}{c}\text { 23\% } \\
\text { "happy" } \\
38 \%\end{array}$ & $81 \%$ & $\begin{array}{c}19 \% \\
\text { "happy" } \\
36 \%\end{array}$ \\
\hline Parents & $83 \%$ & $\begin{array}{c}17 \% \\
\text { "happy" } \\
16 \%\end{array}$ & $100 \%$ & - & & & & \\
\hline \multicolumn{9}{|c|}{ CONFLICT AVOIDING SIGNALS } \\
\hline 3 years & $23 \%$ & $\begin{array}{c}77 \% \\
\text { "happy" } \\
68 \%\end{array}$ & $26 \%$ & $\begin{array}{c}74 \% \\
\text { "happy" } \\
75 \%\end{array}$ & $33 \%$ & $\begin{array}{c}67 \% \\
\text { "happy" } \\
49 \%\end{array}$ & $30 \%$ & $\begin{array}{c}70 \% \\
\text { "happy" } \\
62 \%\end{array}$ \\
\hline 4 years & $31 \%$ & $\begin{array}{c}69 \% \\
\text { "happy" } \\
51 \%\end{array}$ & $27 \%$ & $\begin{array}{c}73 \% \\
\text { "happy" } \\
58 \%\end{array}$ & $33 \%$ & $\begin{array}{c}\text { 67\% } \\
\text { "happy" } \\
49 \%\end{array}$ & $36 \%$ & $\begin{array}{c}64 \% \\
\text { "happy" } \\
37 \%\end{array}$ \\
\hline 5 years & $27 \%$ & $\begin{array}{c}73 \% \\
\text { "happy" } \\
56 \%\end{array}$ & $42 \%$ & $\begin{array}{c}58 \% \\
\text { "happy" } \\
34 \%\end{array}$ & $25 \%$ & $\begin{array}{c}75 \% \\
\text { "happy" } \\
51 \%\end{array}$ & $20 \%$ & $\begin{array}{c}80 \% \\
\text { "happy" } \\
57 \%\end{array}$ \\
\hline Parents & $52 \%$ & $\begin{array}{c}\text { 48\% } \\
\text { "happy" } \\
66 \%\end{array}$ & $93 \%$ & $\begin{array}{c}7 \% \\
\text { "happy" } \\
36 \%\end{array}$ & & & & \\
\hline \multicolumn{9}{|c|}{ CONFLICT DEFUSING SIGNALS } \\
\hline 3 years & $16 \%$ & $\begin{array}{c}84 \% \\
\text { "happy" } \\
54 \%\end{array}$ & $14 \%$ & $\begin{array}{c}\text { 86\% } \\
\text { "happy" } \\
64 \%\end{array}$ & $16 \%$ & $\begin{array}{c}84 \% \\
\text { "happy" } \\
50 \%\end{array}$ & $14 \%$ & $\begin{array}{c}86 \% \\
\text { "happy" } \\
58 \%\end{array}$ \\
\hline 4 years & $13 \%$ & $\begin{array}{c}\text { 87\% } \\
\text { "happy" } \\
55 \%\end{array}$ & $13 \%$ & $\begin{array}{c}87 \% \\
\text { "happy" } \\
50 \%\end{array}$ & $15 \%$ & $\begin{array}{c}85 \% \\
\text { "happy" } \\
45 \%\end{array}$ & $17 \%$ & $\begin{array}{c}83 \% \\
\text { "happy" } \\
45 \%\end{array}$ \\
\hline 5 years & $20 \%$ & $\begin{array}{c}80 \% \\
\text { "happy" } \\
56 \%\end{array}$ & $20 \%$ & $\begin{array}{c}80 \% \\
\text { "happy" } \\
35 \%\end{array}$ & $18 \%$ & $\begin{array}{c}82 \% \\
\text { "happy" } \\
44 \%\end{array}$ & $13 \%$ & $\begin{array}{c}87 \% \\
\text { "happy" } \\
41 \%\end{array}$ \\
\hline Parents & $28 \%$ & $\begin{array}{c}72 \% \\
\text { "happy" } \\
14 \%\end{array}$ & $73 \%$ & $\begin{array}{c}27 \% \\
\text { "happy" } \\
16 \%\end{array}$ & & & & \\
\hline
\end{tabular}

Based on 114 children overall and 40 adults.

Group $(3,4,5)$ by Distress Group (conflict-defusing, conflictavoiding, conflict-escalating) at the different testing times (before training, after training, after 6 months, after 1 year). The following main effects were found: A significant main effect for Age $\left[F_{(2,148.822)}=6.98, p=.002\right.$, partial $\left.\eta^{2}=.14\right]$ and Distress Signal Group $\left[F_{(1.772,84)}=395.36, p=.0001\right.$, partial $\left.\eta^{2}=.83\right]$ as well as Testing Time $\left[F_{(2.823,237.156)}=4.72\right.$, $p=.004$, partial $\left.\eta^{2}=.053\right]$. Significant interactions were shown for Testing Time by Age $\left[F_{(6,84)}=4.94, p=.001\right.$, partial $\left.\eta^{2}=.11\right]$, Distress Signal by Age $\left[F_{(4,84)}=4.298\right.$, $p=.002$, partial $\left.\eta^{2}=.93\right]$ and Testing Time by Distress Signal $\left[F_{(5.643,473.980)}=4.70, p=.001\right.$, partial $\left.\eta^{2}=.53\right]$. Overall, children distinguish conflict-escalating signals better than conflict-avoiding and conflict-defusing signals. They show more correct answers with increasing age and improve after intervention, specifically in the conflict-escalating signal group. In this group, improvements are stable over time (up to 1 year). The 5-year-olds also improve in the conflict-avoiding signal group from before to after intervention, however, this effect is not enduring over time. Interestingly, despite the same rating categories 4 and 5 accepted for conflict-avoiding and conflictescalating signals, children distinguished conflict-avoiding and conflict-escalating signals clearly $(p<.0001)$. Overall, these results show significant differences over time and for the different distress groups, with older children giving more correct answers than younger children. See Figure 5 below for an overview of the results.

Concerning the question if children just learn over time or if results are due to our intervention, we have compared results of children at 4 and 5 years (4-year-olds at initial test act as control group to 3 -year-olds at testing after 1 year when they are 4; 5-year-olds at initial test act as control group to 4 -year-olds at testing after 1 year when they are 5). When comparing these 3-year-olds' reactions after 1 year, they show significantly more correct answers (66\%) compared to 4-yearolds before intervention (55\% correct, $p<.044$ ). Similarly, 4 year-olds after 1 year when they turned 5 demonstrate $76 \%$ correct answers vs. 64\% correct answers in 5-year-olds before intervention start $(p<.025)$. These significant differences between the control and intervention groups indicate that the intervention is successful and causes a significant increase in learning.

\section{Correct Answers and Errors - Adults}

We calculated a repeated measures Anova of Gender (male/female) by Dog Ownership (yes/no) by Distress group (conflict-defusing, conflict-avoiding, conflict-escalating) for Testing Times before and after intervention on percentage of correct answers. Gender and Dog Ownership yielded no significant results, therefore the analysis was calculated with Distress Signal group (conflict-defusing, conflict-avoiding, conflict-escalating) and Testing Times (before and after intervention) on percent correct responses. We found a highly significant main effect for Testing Times $\left[F_{(1,39)}=311.49\right.$, $p=.0001$, partial $\eta^{2}=.89$ ] with better results overall after intervention and a highly significant main effect for Distress Signal Group showing differences between distress signal groups are perceived $\left[F_{(2,78)}=173.73, p=.0001\right.$, partial $\left.\eta^{2}=.82\right]$. A highly significant interaction between Testing Time and Distress Signal also emerged $\left[F_{(2,78)}=26.01, p=\right.$ .0001 , partial $\eta^{2}=.40$ ] demonstrating higher rates of correct answers with higher distress as well as rates of correct answers rising from conflict-defusing via avoiding to escalating and all scores being higher after intervention. Results in overview in Figure 6 below.

Interestingly, if we calculate results on a stricter criterium, i.e., only count as correct for conflict-escalating those answers that said "very unhappy/very angry," all main effects and interactions stay intact, however, performance of adults drops in the conflictavoiding category to $40 \%$ - and in children to 35,51 -, and $60 \%$ respectively for 3-, 4-, and 5-year-olds after intervention. 

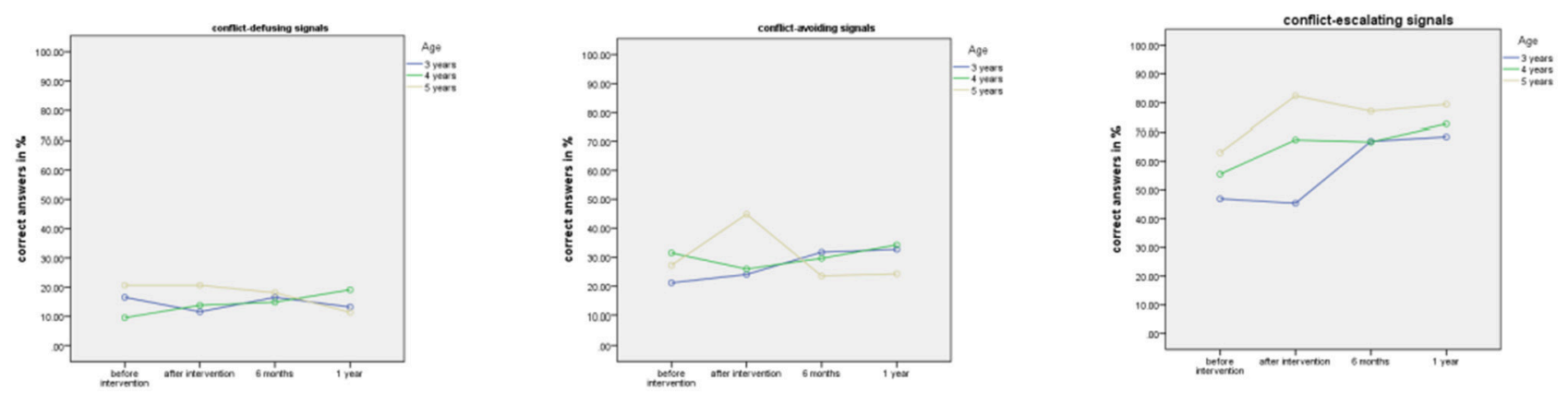

FIGURE 5 | Results in overview for children by signal group before and after intervention, at 6 months and 1 year.

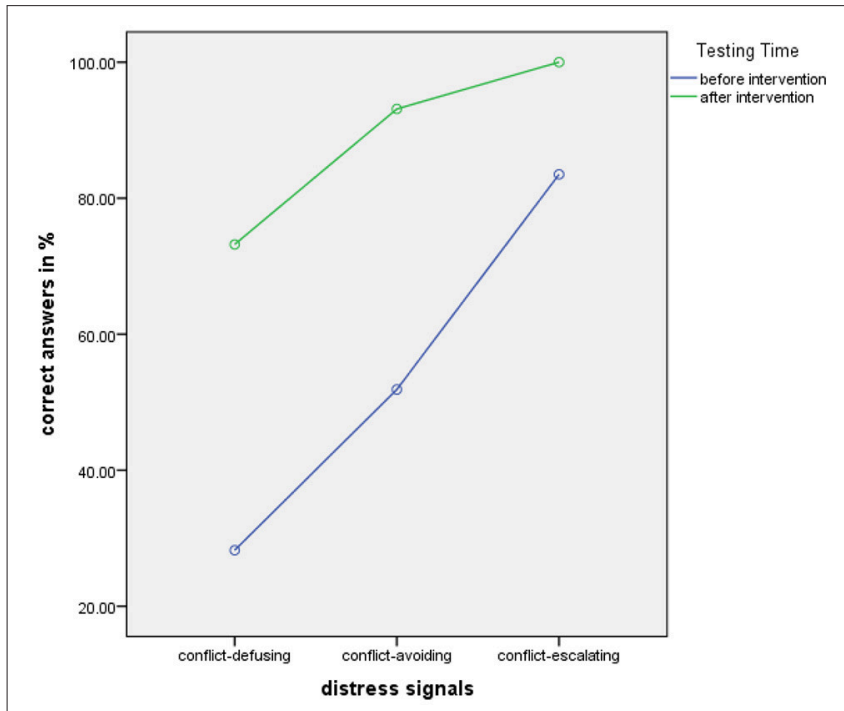

FIGURE 6 | Percent correct scores for adults by distress signal group before and after intervention.

\section{Additional Observations-Children's Initial Perceptions}

In addition to the quantitative data described above, we also would like to provide some additional observations. While we were working with the children, they often commented on the videos. The quotes below give an impression of children's thinking and reflect the most frequent comments, see Table 3 below.

These comments were frequently made and show that children often anthropomorphise dogs and try to find an explanation that would be appropriate to explain human behavior, but unfortunately does not fit the dog's signaling intentions.

We would furthermore like to report, so far also only anecdotal comments of parents stating that they frequently provoked distress-signaling behaviors, for example, like lip/noselicking in their dog, as the family found it funny. However, having learned about dogs' distress signaling in the intervention, the
TABLE 3 | Dog signaling behaviors and children's perceptions and interpretations.

\begin{tabular}{|c|c|}
\hline Dog signaling & Child's perception and interpretation \\
\hline Dog growling/snarling & $\begin{array}{l}\text { "Is really happy and makes a funny noise!" "I } \\
\text { could go and cuddle and kiss it - it is so happy!" }\end{array}$ \\
\hline Dog staring/stiffening up & "It's looking at me - it likes me!" \\
\hline Dog lying down, legs up & "It wants me to tickle its belly!" \\
\hline Dog crouching, tail tucked & $\begin{array}{l}\text { "It's sad - let me go and cuddle it to cheer it } \\
\text { up!" }\end{array}$ \\
\hline Dog hiding under couch & "Surely, dog wants to play hide and seek!" \\
\hline Dog is yawning & "Must be tired!" \\
\hline Dog shows nose/lip-licking & "Something tasty on its nose" \\
\hline
\end{tabular}

adults were upset that they and their children might have caused their dog distress and commented that they will change their (and their children's) behavior, thus contributing to a safer home environment for all and to dogs' welfare. Further research will need to be carried out to investigate this systematically.

\section{DISCUSSION}

Results show that children and adults profit from the intervention and improve their knowledge of dogs' stress signaling significantly. When performing analyses over time we found that, overall, learning effects are still highly significant in children after 6 months and 1 year despite no training taking place in the meantime-thus, the intervention works successfully, even over the duration of 1 year.

A closer look at the error results shows us the areas in which the intervention has worked most successfully, and also the areas in which we need to invest more training with children and parents alike. We have very good success teaching all age groups of children, even young children of 3 years, and parents the meaning of conflict-escalating distress signals. They learn to understand, recognize and correctly interpret the signals and the learning success is still evident after 1 year. This is an important success as dogs showing their teeth or snarling or biting, pose a significant risk to children if these approach the dogs displaying such signaling. We have good to moderate success in training 
especially older (5-year-old) children and parents on conflictavoiding distress signals. However, the data also show that all participants, including adults, find the more subtle signals of dogs' distress hardest to judge. Here, after intervention, only adults show excellent improvements. More research is needed to analyse these signals and how they are perceived in detailed examinations of this in future studies.

One could also question whether children's increase in knowledge is due to general learning and increase in maturityhowever, the results of the 4- and 5-year-olds clearly contradict this as children who have taken part in the interventions (3and 4-year-olds tested after 1 year when they turned 4 and 5 respectively) show significantly better results than the 4 -and 5year-olds at the start of the study (before intervention). Thus, our intervention has clearly improved their knowledge over time compared to the control group. To investigate the role of the intervention in light of children's learning and general maturity over time, it could be useful to devise larger studies with independent control groups, hence requiring significantly larger funding sources.

Overall, it becomes evident from this data that it is possible to educate adults and children to understand dogs' distress signaling. Adults profited from the intervention throughout all distress categories and show clear and significant learning effects. Thus, it is advisable to teach dog signaling to parents, dog owners, dog trainers, veterinary students and the wider public. The short intervention is easy to use and leads to significant improvements in knowledge, recognition and interpretation straight away and with enduring effect.

It has also become clear which areas need further attention and research-while our intervention works very well with adults and also with older children, it has to be adapted to improve especially the younger children's understanding, especially of the more subtle distress signals in dogs. Further research will need to explore how children process the signals and how to teach these signals best.

Our background measures of dog ownership, SES/parental education showed that there were no effects of any of these factors-in other words, neither children's nor parents' performance was better if, for example, they owned a dog, had a higher SES/education. Instead, performance was independent of these factors.

There was also no difference between children seeing novel stimuli in all test phases or the same stimuli again. This is useful to know for the future creation of interventions as we can now be confident that we do not need to increase the amount of novel stimuli to be shown in order to train and assess children on dog body signaling.

Finally, children's utterances illustrated how they perceivedand misinterpreted-dogs' body language. Further quantitative as well as qualitative research in this area is warranted and could help develop additional dog bite prevention tools.

By assessing if our intervention works, we have undertaken the first step toward preventing misunderstandings and risk escalation due to addressing the current lack of knowledge and replacing it with knowledge that is stable over time. In the case of conflict-escalating signals, all participants showed significant improvements in knowledge over time.

Further steps next to teaching children and parents Knowledge of stress signaling (step 1) and Recognition and correct interpretation of stress signaling in context (step 2) are to Adapt the action. Having created awareness of the situation, insight to act accordingly should follow (step 3). Finally, Repeat recognition of future triggers and contexts and avoidance of risk (step 4) need to follow to effectively implement the taught knowledge. Further research will have to assess how to achieve these aims best.

In particular, future studies should address how best to implement the above so that beyond recognizing and understanding the signals, specific human actions and contexts wherein the dog presents these signs are recognized. It will also be useful to investigate if parents-or other educators-can guide and educate children to be aware of specific risk contexts. Concerning parental supervision, it would be interesting to find out to what extent they supervise child and dog and stop children from engaging in risky contexts with their dog in the first place. Furthermore, it would be beneficial to follow up in how far the welfare of family and dog are compromised after escalations have happened as well as investigate the role of professional help from a veterinary behavioral specialist.

Finally, and importantly, we assume that dogs will benefit from children and adults having been taught how to read their distress signals. This increased understanding will mean that dogs are better understood, and if humans apply their knowledge appropriately this will lead to greater wellbeing of the dog living within a family household.

\section{CONCLUSION}

This project is the first to offer an intervention to enhance children's and adults' abilities to interpret dog signaling correctly.

We investigated how children perceive and categorize dogs' body language and interpret their signals and we then trained them and were able to improve their knowledge, recognition and interpretation skills.

We showed very good results in improving the potentially very dangerous misunderstandings of dogs' conflict-escalating distress and threat signals. For example, a snarling dog showing teeth which children often misinterpreted as a happy dog, can now be corrected-children showed significant improvements that were stable over time. We have shown successfully that we can significantly improve all participants' abilities to recognize and understand these signals and enable all participant groups to avoid escalating risk situations-our intervention works especially well for these high risk situations. This is especially useful asif such escalation occurs-it should be stopped to avoid risk of dog bite incidents and continued stress to the dog. Crucially, as our intervention furthers understanding of conflict-defusing and conflict-avoiding signals, hopefully, this may help to avoid risk escalation.

We have revealed the extent of children's and adults misinterpretation errors for the first time, and we have shown areas in which children and adults make most errors. We have 
also shown that we can teach adults and children successfully to learn, recognize and interpret the signals correctly.

With this new knowledge we enhance the currently scarce scientific database on children's and adults' interpretation abilities of dog signaling. We can now also address not only the most dangerous misinterpretations, but also commit ourselves to creating awareness of the less well understood and most frequently misunderstood signaling behaviors of dogs in order to avoid escalation of risk. The materials used can be further developed into an awareness raising intervention that is more widely usable for children and adults. For future effective prevention the above mentioned steps of implementation need to follow and, in turn, also be assessed as to their effectiveness.

In sum, we have now got a solid knowledge base about how children and adults look at and perceive dogs and (mis)interpret their behavior.

Our study was able to close these particular knowledge gaps, establish the necessary knowledge for the first time and therefore significantly advance the scientific knowledge in this area. Our study was also able to show that we can teach dog signaling successfully, and it outlines the current limitations.

Veterinarians will profit from these results insofar as they can help to raise awareness of the existing knowledge gaps in both adults and children.

Our study can also serve as an example of good practice in that we have evaluated the learning effects of the intervention cross-sectionally and longitudinally, as well as using additional measures.

In the future, integrated research projects including child psychology, veterinary, medical, educational and other social sciences can be developed as a result of these efforts and produce research with impact on One Health-related injury prevention challenges.

\section{REFERENCES}

1. Fine AH. (Ed). Handbook of Animal Assisted Therapy. London: Academic Press (2015).

2. Brelsford V, Meints K, Gee, N, Pfeffer K. Animal-assisted interventions in the classroom - a systematic review. Int J Environ Res Public Health 22 (2017) 14:E669. doi: 10.3390/ijerph14070669

3. Purewal R, Christley R, Kordas K, Joinson C, Meints K, GeeN et al. Companion Animals and Child/Adolescent Development: A systematic review of the evidence. Int J Environ Res Public Health (2017) 14:234. doi: 10.3390/ijerph14030234

4. Raina P, Walter-Toews D, Bonnett B, Woodward C, Abernathy T. Influence of companion animals on the physical and psychological health of older people: an analysis of a one-year longitudinal study. J Am Geriatr Soc. (1999) 47:323-9. doi: 10.1111/j.1532-5415.1999.tb0 2996.x

5. Australian Veterinary Association (AVA). Animal Health Alliance publication, Pet ownership in Australia. (2016). Available online at: http://www.ava.com.au/news/media-centre/hot-topics-4

6. American Veterinary Medical Foundation (AVMA). US Pet Ownership and Demographic. (2016). Available online at: https://www.avma.org/KB/ Resources/Statistics/Pages/Market-research-statistics-US-pet-ownership. aspx

\section{AUTHOR CONTRIBUTIONS}

KM conceived and designed the research project. TD fed back on the project proposals, contributed to their improvement and contributed the majority of dog videos. As behavior specialist, she also carefully assessed and commented on the video pool and helped select appropriate videos. KM and VB contributed to all aspects of the research itself from planning to testing to data analysis and writing up results. TD also contributed to initial design and planning and to writing the manuscript.

\section{FUNDING}

This research was co-funded by the Eunice Kennedy Shriver National Institute of Child Health and Human Development (NICHD) and the WALTHAM ${ }^{\circledR}$ Center for Pet Nutrition, a division of Mars, Incorporated. The project described was supported by Grant Number 1R03HD071161-01 from the Eunice Kennedy Shriver National Institute of Child Health \& Human Development and Mars-WALTHAM ${ }^{\circledR}$.

\section{ACKNOWLEDGMENTS}

We would like to thank our funders and all nurseries and schools, parents and children who took part in this research-it would not have been possible without your help.

We would also like to thank dog behavior specialists Prof. Daniel Mills and Dr. Hannah Wright, both University of Lincoln, UK, for taking the time and great care to assess and comment on our video selection and to help us with the selection process for final testing. We would furthermore like to acknowledge and thank Geert De Bolster (dog rehabilitation trainer, Belgium) for providing additional videos.

7. Millot JL, Filiatre JC, Eckerlin A, Gagnon AC, Montagner H. Olfactory cues in the relations between children and their pet dogs. Appl Anim Behav Sci. (1986) 19:189-95 doi: 10.1016/0168-1591(87)90216-4

8. Filiatre JC, Millot JL, Montagner H. New data on communication behaviour between the young child and his pet dog. Behav Processes (1986) 12:33-44. doi: 10.1016/0376-6357(86)90068-9

9. Borgi M, Cogliati-Dezza I, Brelsford V, Meints K, Cirulli F. Baby schema in human and animal faces induces cuteness perception and gaze allocation in children. Front Psychol. (2014) 5:411. doi: 10.3389/fpsyg.2014. 00411

10. Borgi M, Cirruli F. Attitudes toward animals in Kindergarten children: Species preferences. Anthrozoös (2015) 28:45-59. doi: 10.2752/089279315X14129350721939

11. Murray J, Browne WA, Roberts M, Whitmarsh A, Gruffydd-Jones T. Number and ownership profiles of cats and dogs in the UK. The Veterinary record (2010) 166:163-8. doi: 10.1136/vr.b4712.

12. Murray JK, Gruffydd-Jones TJ, Roberts MA, Browne WJ. Assessing changes in the UK pet cat and dog populations: numbers and household ownership. Veterinary Record (2015) 177:259. doi: 10.1136/vr.1 03223

13. Pet Food manufacturers Association (PMFA). Pet Data Report. (2017). Available online at https://www.pfma.org.uk/_assets/docs/Data\%20report/ PFMA-Pet-Population-Report\%202017_WEB.pdf 
14. HSUS (Humane Society of the United States) (2011). Annual Report 2011. Available online at: http://www.humanesociety.org/about/overview/ financials/2011_annual_report/annual_report_2011.html

15. GfK (2017). Available online at: https://www.gfk.com/fileadmin/user_ upload/website_content/Global_Study/Images/Infographics_Fullsize/Pet_ Ownership_Countries_Web-RGB-GfK-Infographic.jpg

16. Gisle L, Buziarsist J, Van der Heyden J, Demarest S, Miermans PJ, Sartor F, et al. Health Enquiry by Interview, IPH/EPI Report $\mathrm{N}^{\circ}$ (2002). 2002-22.

17. Gilchrist J, Sacks JJ, White DD, Kresnow M-J. Dog bites: Still a problem? Injur Prevention. (2008) 14:296-30. doi: 10.1136/ip.2007.016220

18. Horisberger U, Stärk KDC, Rüfenacht J, Pillonel C, Steiger A. The epidemiology of dog bite injuries in Switzerland - characteristics of victims, biting dogs and circumstances. Anthrozoös (2004) 17:320-39. doi: 10.2752/089279304785643212

19. Kahn A, Robert E, Piette D, De Keuster T, Lamoureux J, Leveque A. Prevalence of dog bites in children. Telephone Surv Eur J Pediatr. (2004) 163:424. doi: 10.1007/s00431-004-1456-3

20. Ozanne-Smith J, Ashby K, Stathakis VZ. Dog bite and injury prevention:analysis, critical review and research agenda. Injur Prevent. (2007) 7:321-6. doi: 10.1136/ip.7.4.321

21. HSCIC (Health and Social Care Information Centre). Accident and Emergency Attendances in England - 2014-15. (2015). Available online at: https://digital.nhs.uk/data-and-information/publications/statistical/ hospital-episode-statistics-for-admitted-patient-care-outpatient-andaccident-and-emergency-data/provisional-monthly-hospital-episodestatistics-for-admitted-patient-care- outpatients-and-accident-andemergency-data-april-2014-to-february-2015 Accessed May 30, 2018.

22. Wilson F, Dwyer F, Bennet P. Prevention of dog bites: evaluation of a brief educational intervention program for preschool children. J Community Psychol. (2003) 31:75-86. doi: 10.1002/jcop.10038

23. Cornelissen JMR, Hopster H. Dog bites in the Netherlands: a study of victims, injuries, circumstances and aggressors to support evaluation of dog breed specific legislation. The Veterinary J. (2010) 186:292-8. doi: 10.1016/j.tvjl.2009.10.001

24. HSCIC (Health and Social Care Information Centre). Admissions caused by dogs and other mammals. UK: Health and Social Care Information Centre. (2014). Available online at: http://www.hscic.gov.uk/catalogue/PUB14030/ prov-mont-hes-admi-outp-ae-April\%202013\%20to\%20January\%202014toi-rep.pdf

25. Schalamon J, Ainoedhofer H, Singer G, Petnehazy T, Mayr J, Kiss K, et al. Analysis of dog bites in children who are younger than 17 years. Pediatrics (2006) 117:e374-9. doi: 10.1542/peds.2005-1451

26. HSCIC (Health and Social Care Information Centre). Hospital admissions caused by dogs on the rise say provisional figures, which highlight seasonal and regional patterns. (2012). Available onlina at: http://www.ic.nhs.uk/ news-and-events/news/hospital-admissions-caused-by-dogs- on-the-risesay-provisional-figures-which-highlight-seasonal-and-regional-patterns (Accessed June 20, 2012).

27. Quirk JT. Non-fatal dog bite injuries in the USA, 2005 - 2009. Public Health (2012) 126:300-2. doi: 10.1016/j.puhe.2012.01.010

28. Beck AM, Jones BA. Unreported dog bites in children. Public Health Rep. (1985) 100:315-21.

29. Spiegel IB. A pilot study to evaluate an elementary schoolbased dog bite prevention program. Anthrozoös (2000) 13:164-73. doi: 10.2752/089279300786999789

30. Westgarth C, Brooke M, Christley RM. How many people have been bitten by dogs? A cross-sectional survey of prevalence, incidence and factors associated with dog bites in a UK community. J Epidemiol Commun Health (2018) 72:331-6. doi: 10.1136/jech-2017-209330

31. Messam LL, Kass PH, Chomel BB, Hart LA. The human-canine environment: a risk factor for non-play bites? Veterinary J. (2008) 177:20515. doi: 10.1016/j.tvjl.2007.08.020

32. Castrodale LJ. Hospitalizations resulting from dog bite injuries in Alaska, 1991 - 2002. Int J Circumpolar Health (2007) 66:320-7. doi: 10.3402/ijch.v66i4.18273

33. De Keuster T, Lamoureux J, Kahn A. Epidemiology of dog bites: a Belgian experience of canine behaviour and public health concerns. Veterinary J. (2006) 172:482-7. doi: 10.1016/j.tvjl.2005.04.024
34. Lang ME, Klassen T. Dog bites in Canadian children: a five year review of severity and emergency department management. Canad J Emerg Med. (2005) 7:309-14. doi: 10.1017/S1481803500014494

35. Rosado B, Garcia-Belenguer S, Leon M, Palacio J. Spanish dangerous animals act: Effect on the epidemiology of dog bites. J Veterinary Behav. (2007) 197:166-74. doi: 10.1016/j.jveb.2007.07.010

36. Holmquist L, Elixhauser A. Emergency department visits and inpatient stays involving dog bites, 2008. In: Holmquist L, Elixhauser A, editors. Healthcare cost and utilization project. Washington, DC: Agency for Healthcare Research and Quality (2010). 1-14.

37. Insurance Information Institute and State Farm. Dog Bite Liability. (2014). Available online at: http://www.iii.org/issue-update/dog-bite-liability

38. Bennett P, Righetti J. The Delta Dog Safe ${ }^{\mathrm{TM}}$ Strategy. In: Proceedings of the 2001 Annual Urban Animal Management Conference. Melbourne (2001).

39. Responsible dog ownership. (2013). Available online at: www.publications. parliament.uk/pa/cm201213/cmhansrd/cm130226/halltext/130226h0001. htm

40. Mannion C, Graham A, Shepherd K, Greenberg D. Dog bites and maxillofacial surgery: what can we do? Br J Oral Maxillofacial Surg. (2015) 56:479-84. doi: 10.1016/j.bjoms.2015.02.022

41. De Keuster T, Overall KL. Preventing dog bite injuries: the need for a collaborative approach. Veterinary Record (2011) 169:341-2. doi: 10.1136/vr.d5809

42. Orritt R. Dog ownership has unknown risks but known health benefits: we need evidence based policy. BMJ (2014) 349:g4081. doi: 10.1136/bmj.g4081

43. Beaver B, Baker MD, Gloster RC, Grant WA, Harris JM, Hart B, et al. A community approach to dog bite prevention. J Am Veterinary Med Assoc. (2001) 218:1732-49. doi: 10.2460/javma.2001.218.1732

44. Kahn A, Bauche P, Lamoureux J, Dog Bites Research Team. Child victims of dog bites treated in emergency departments: a prospective child study. Eur J Pediatr. (2003) 162:254-8. doi: 10.1007/s00431-002-1130-6

45. Reisner IR, Nance ML, Zeller JS, Houseknecht EM, Kassam-Adams N, Weibe DJ. Behavioral characteristics associated with dog bites to children presenting to an urban trauma center. Injury Prevent. (2011) 17:348-53. doi: 10.1136/ip.2010.029868

46. Brogan TV, Bratton SL, Dowd MD, Hegenbarth MA. Severe dog bites in children. Pediatrics (1995) 96:947-50.

47. Love M, Overall K. How anticipating relationships between dogs and children can help prevent disasters. J Am Veterinary Med Assoc. (2001) 19:446-51. doi: 10.2460/javma.2001.219.446

48. Oxley JA, Christley R, Westgarth C. Contexts and consequences of dog bite incidents. J Veterinary Behav. (2018) 23:33-9. doi: 10.1016/j.jveb.2017.10.005

49. Arhant C, Beetz AN, Troxler J. Caregiver reports of interactions between children up to 6 years and their family dog - Implications for dog bite prevention. Front Veterinary Sci. (2017) 4:130. doi: 10.3389/fvets.2017.00130

50. Mitchell RB, Nanez G, Wagner JD, Kelly J. Dog bites of the scalp, face and neck in children. Laryngoscope (2003) 113:492-5. doi: 10.1097/00005537-200303000-00018

51. Peters V, Sottiaux M, Appelboom J, Kahn A. Posttraumatic stress disorder after dog bites in children. J Pediatr. (2004) 144:121-2. doi: 10.1016/j.jpeds.2003.10.024

52. Boat BW, Dixon CA, Pearl E, Thieken L, Bucher SE. Pediatric dog bite victims: a need for a continuum of care. Clin Pediatr. (2012) 51:473-7. doi: $10.1177 / 0009922811435504$

53. Mathews JR, and Lattal $\mathrm{K}$ A. A behavioural analysis of dog bites to children. J Dev Behav Pediatr. (1994) 15:44-52. doi: 10.1097/00004703-199402000-00008

54. Sacks JJ, Sattin RW, Bonzo SE. Dog bite-related fatalities from 1979 through 1988. J Am Med Assoc. (1989) 262:1489-92. doi: 10.1001/jama.1989.03430110079032

55. Reisner I, Shofer F, Nance M. Behavioral assessment of child-directed canine aggression. Injury Prevention (2007) 13:348-51. doi: 10.1136/ip.2007.015396

56. Meints K, De Keuster T. Brief report: don't kiss a sleeping dog: the first assessment of "the blue dog" bite prevention program. J Pediatr Psychol. (2009) 34:10. doi: 10.1093/jpepsy/jsp053

57. Kerswell KJ, Bennett PJ, Butler KL, Hemsworth PH. Self-reported comprehension ratings of dog behaviour by puppy owners. Anthrozoös (2009) 22:183-93. doi: 10.2752/175303709X434202 
58. Mariti C, Gazzano A, Moore JL, Baragli P, Chelli L, Sigheri C. Perception of dogs' stress by their owners. J Veterinary Behav. (2012) 7:213-9. doi: 10.1016/j.jveb.2011.09.004

59. Bloom T, Friedmann H. Classifying dogs' (Canis familiaris) facial expressions from photographs. Behavioral Processes (2013) 96:1-10. doi: 10.1016/j.beproc.2013.02.010

60. Meints K, Racca A, and Hickey N. How to prevent dog bite injuries? Children misinterpret dogs' facial expressions. Inj Prevent. (2010) 16:A68. doi: 10.1136/ip.2010.029215.246

61. Lakestani NN, Donaldson M, Verga M, Waran N. Keeping children safe: how reliable are children at interpreting dog behavior? In: Proceedings of the 40 th International Congress of the International Society for Applied Ethology, 233. ISAE Committee: Cranfield University Press (2006).

62. Tami G, Gallagher A. Description of the behavior of domestic dog (Canis familiaris) by experienced and inexperienced people. Appl Animal Behav Sci. (2009) 120:159-69. doi: 10.1016/j.applanim.2009.06.009

63. Wan M, Bolger N, Champagne FA. Human perception of fear in dogs varies according to experience with dogs. PLoS ONE (2012) 7:e51775. doi: 10.1371/journal.pone.0051775

64. Reisner IR, Shofer FS. Effects of gender and parental status on knowledge and attitudes of dog owners regarding dog aggression toward children. J Am Vet Med Assoc. (2008) 233:1412-9. doi: 10.2460/javma.233.9.1412

65. Dixon CA, Mahabee-Gittens EM, Hart KW, Lindsell CJ. Dog bite prevention: An assessment of child knowledge. J Pediatr. (2012) 160:337-41. doi: 10.1016/j.jpeds.2011.07.016

66. Chapman S, Cornwall J, Righetti J, Sung L. Preventing dog bites in children: Randomized controlled trial of an educational intervention. Br Med J. (2000) 320:1512-3. doi: 10.1136/bmj.320.7248.1512

67. Lakestani N, Donaldson ML. Dog bite prevention: effect of a short educational intervention for preschool children. PLoS ONE (2015) 10:e0134319. doi: 10.1371/journal.pone.0134319

68. Shen J, RouseJ, Godbole M, Wells HL, Boppana S, Schwebel DC. Systematic review: interventions to educate children about dog safety and prevent pediatric dog-bite injuries: a meta-analytic review. J Pediatr Psychol. (2017) 42:779-91. doi: 10.1093/jpepsy/jsv164

69. Dixon CA, Pomerantz WJ, Hart KW, Lindsell CJ, Mahabee-Gittens EM. An evaluation of a dog bite prevention intervention in the pediatric emergency department. J Trauma Acute Care Surg. (2013) 75:S308-12. doi: 10.1097/TA.0b013e31829be2bc

70. McGreevy PD, Starling M, Branson NJ, Cobb ML, Calnon D. An overview of the dog-human dyad and ethograms within it. J Vet Beh Clin App Res. (2012) 7:103-17. doi: 10.1016/j.jveb.2011.06.001

71. Rugaas T. On Talking Terms With Dogs: Calming Signals, 2 nd ed. Wenatchee, WA: Dogwise publishing (2006)

72. Shepherd K. Development of behavior, social behavior and communication in dogs. In: Horwitz D, Mills D, and Heath S, editors. BSAVA Manual of Canine and Feline Behaviour Medicine. Gloucester, UK: British Small Animal Veterinary Association (2002). pp. 8-20.

73. Shepherd, K. Behavioural medicine as an integral part of veterinary practice. In: Horwitz D and Mills D, editors. BSAVA Manual of Canine and Feline Behaviour, 2nd edn. (2009). pp 10-23.

74. Mariti C, Falaschi C., Zilocchi M, Fatjó J, Sighieri C, Ogi A, et al. Analysis of the intraspecific visual communication in the domestic dog (Canis familiaris): a pilot study on the case of calming signals. J Veterinary Behav. (2017) 18:49-55. doi: 10.1016/j.jveb.2016. 12.009

75. Firnkes A, Bartels A, Bidoli E, and Erhard M. Appeasment signals used by dogs during dog-human communication. J Vet Sci. (2017) 19:35-44. doi: $10.1016 /$ j.jveb.2016.12.012

76. Kuhne F. Behavioural responses of dogs to dog-human social conflict situations. Appl Anim Behav Sci. (2016) 182:38-43. doi: 10.1016/j.applanim.2016.05.005

77. Overall KM. Manual for clinical behavioural medicine for dogs and cats. St. Louis, MO; USA: Elsiever Mosby (2013).

78. Gielen C, Sleet D. Application of behavior-change theories and methods to injury prevention. Epidemiol Rev. (2003) 25:65-76. doi: $10.1093 /$ epirev/mxg004
79. Call J, Bräuer J, Kaminski J, Tomasello M. Domestic dogs (Canis familiaris) are sensitive to the attentional state of humans. J Comp Psychol. 117:257-63. doi: 10.1037/0735-7036.117.3.257

80. Gacsi M, Miklosi A, Varga O, Topál J, Csanyi V. (2004). Are readers of our face readers of our minds? Dogs (Canis familiaris) show situation dependent recognition of human's attention. Anim Cogn. (2003) 7:144-53. doi: 10.1007/s10071-003-0205-8

81. Gácsi M, Maros K, Sernkvist S, Miklósi Á. Does the owner provide a secure base? Behavioral and heart rate response to a threatening stranger and to separation in dogs. J Vet Behav. (2009) 4:90-1. doi: 10.1016/j.jveb.2008.09.042

82. Hare B, Tomasello M. Human-like social skills in dogs? Trends Cogn Sci. 9:439-44. doi: 10.1016/j.tics.2005.07.003

83. Horn L, Huber L, Range F. The Importance of the Secure Base Effect for Domestic Dogs - Evidence from a Manipulative Problem-Solving Task. PLoS ONE (2013) 8:e65296. doi: 10.1371/journal.pone.0065296

84. Racca A, Guo K, Meints K, Mills DS. Reading faces: differential lateral gaze bias in processing canine and human facial expressions in dogs and 4-yearold children. PLOS ONE (2012) 7:e36076. doi: 10.1371/journal.pone.0036076

85. Racca A, Amadei E, Ligout S, Guo K, Meints K, Mills D. Discrimination of human and dog faces and inversion responses in domestic dogs (Canis Familiaris). Anim Cogn. (2010) 13:525-33. doi: 10.1007/s10071-009-0303-3

86. Guo K, Meints K, Hall C, Hall S, Mills D. Left gaze bias in humans, rhesus monkeys and domestic dogs. Animal Cogn. (2009) 12 409-18. doi: 10.1007/s10071-008-0199-3

87. Kaminski J, Templemann S, Call J, Tomasello M. Domestic dogs comprehend human communication with ironic signs. Dev Sci. (2012) 12:831-7. doi: $10.1111 / j .1467-7687.2009 .00815 . x$

88. Kaminski J, Schulz L, Tomasello M. How dogs know communication is intended for them. Dev. Sci. (2012) 222-32. doi: 10.1111/j.1467-7687.2011.01120.x

89. Huber L, Racca A, Scaf B, Viranyi Z, Range F. Discrimination of familiar faces in dogs (Canis familiaris) Learn Motiv. (2013) 44:258-69. doi: 10.1016/j.lmot.2013.04.005

90. Somppi S, Törnqvist H, Hänninen L, Krause CM, and Vainio O. How dogs scan familiar and inverted faces: an eye movement study. Animal Cogn. (2014) 17:793-803. doi: 10.1007/s10071-013-0713

91. Yong $\mathrm{MH}$, Ruffman $\mathrm{T}$. Is that fear? Domestic dogs use of social referencing signals from an unfamiliar person. Behav Process. (2015) 10:7481. doi: 10.1016/j.beproc.2014.09.018

92. Piotti P, Kaminski J. Do dogs provide information helpfully? PLoS ONE (2016) 11:e0159797. doi: 10.1371/journal.pone.0159797

93. Fine A, Gee N. How Animals Help Students Learn: Research and Practice for Educators and Mental-Health Professionals. New York, NY: Routledge (2017).

94. Gee NR, Fine A, Schuck S. Animals in educational settings: research and practice. In: Fine A.H, editor. Handbook of Animal-Assisted Therapy. London: Academic Press (2015). pp. 195-210.

95. Hall SS, Gee NR, Mills DS. Children reading to dogs: a systematic review of the literature. PLoS ONE (2016) 11:e0149759 doi: 10.1371/journal.pone.0149759

96. O'Haire ME. Animal-assisted intervention for Autism Spectrum Disorder: a systematic literature review. J Autism Dev Disord. (2013) 43:1606-22. doi: 10.1007/s10803-012-1707-5

97. Kamioka H, Okada S, Tsutani K, Park H, Okuizumi H, Handa S, et al. Effectiveness of animal-assisted therapy: A systematic review of randomized controlled trials. Complement Ther Med. (2014) 22:371-90. doi: 10.1016/j.ctim.2013.12.016

98. Maujean A, Pepping CA, Kendall E. A systematic review of randomized controlled trials of animal-assisted therapy on psychosocial outcomes. Anthrozoös (2015) 28:23-36. doi: 10.2752/089279315X14129350721812

99. Davies TN, Scalzo R, Butler E, Stauffer M, Farah YN, Perez S, et al. Animal-assisted interventions for children with autism spectrum disorder: a systematic review . Educ Train Autism Dev Disabilit. (2015) 50:316-29.

100. Faul F, Erdfelder E, Lang, AG. G*Power 3: A flexible statistical power analysis program for the social, behavior, and biomedical sciences. Behav Res Methods (2007) 39:175-91. doi: 10.3758/BF031 93146 
101. Gustavson K, von Soest T, Karevold E, Røysam E. Attrition and generalizability in longitudinal studies: findings from a 15year population-based study and a Monte Carlo simulation study. BMC Public Health (2012) 12:918. doi: 10.1186/1471-2458$12-918$

102. Flom R, Whipple H, Hyde D. Infants' intermodal perception of canine (Canis familiaris) facial expressions and vocalizations. Dev Psychol. (2009) 45:1143-51. doi: 10.1037/a0015367

103. Pongrácz P, Molnár C, Dóka A, Miklósi A. Do children understand man's best friend? Classification of dog barks by pre-adolescents and adults. Appl Animal Behav Sci. (2011) 135:95-102. doi: 10.1016/j.applanim.2011. 09.005

104. Meints K, Woodford A. Lincoln Infant Lab Package 1.0: A new programme package for IPL, Preferential Listening, Habitauation and Eye-tracking. \{WWW doucument: Computer Software and Manual\} (2008). available online at: http://www.lincoln.ac.uk/psychology/babylab.htm

105. Norman G. Likert scales, levels of measurement and the "laws" of statistics. Adv in Health Sci Education (2010) 15:625-32. doi: $10.1007 /$ s10459-010-9222-y
106. Carifio J, Perla RJ. Ten common misunderstandings, misconceptions persistent myths and urban legends about Likert scales and Likert response formats and their antidotes. J Soc Sci. (2008) 3:106-16. doi: 10.3844 /jssp.2007.106.116

107. Tsekouras D. The effect of rating scale design on extreme response tendency in consumer product ratings. Int J Electronic Commerce (2017) 21:270-96, doi: 10.1080/10864415.2016.1234290

Conflict of Interest Statement: The authors declare that the research was conducted in the absence of any commercial or financial relationships that could be construed as a potential conflict of interest.

Copyright (C) 2018 Meints, Brelsford and De Keuster. This is an open-access article distributed under the terms of the Creative Commons Attribution License (CC BY). The use, distribution or reproduction in other forums is permitted, provided the original author(s) and the copyright owner(s) are credited and that the original publication in this journal is cited, in accordance with accepted academic practice. No use, distribution or reproduction is permitted which does not comply with these terms. 